\title{
Tingkat percaya diri atlet panahan Cimahi Mandiri Archery Club
}

\section{Confidence level of archery athletes at Cimahi Mandiri Archery Club}

\author{
Veny Juniani Hardi ${ }^{1}$, Ali Budiman ${ }^{2}$, Imam Riyadi ${ }^{3}$ \\ 1,2,3 Program studi PJKR, STKIP Pasundan, Cimahi, Jawa Barat, 40512, Indonesia
}

\begin{abstract}
Abstrak
Tujuan penelitian ini adalah Untuk mengetahui tingkat kepercayaan diri atlet panahan club cumahi mandiri archery club yang berada di kota cimahi, Metode penelitian yang digunakan dalam penelitian ini adalah penelitian deskriptif. Metode ini digunakan untuk mendapatkan data dari hasil jawaban pada angket. Populasi dalam penelitian ini atlet POPDA Cimahi Mandiri Archery Club, Sampel yang di gunakan adalah 18 atlet. Instrumen yang digunakan pada penelitian ini adalah angket yang di sebar melalui google form. Analisis data yang digunakan dalam penelitian ini terdapat pada data utama yaitu soal tes .Pengolahan data dilakukan dengan cara membuat google form. Data yang telah dikumpulkan kemudian dianalisis dengan bantuan Ms Excel. Hasil dalam penelitian ini adalah 88,89\% tingkat percaya diri pada atlet POPDA Cimahi Mandiri Archery club merasakan adanya pengaruh dari tingkat percaya diri terhadap hasil tembakan dan dapat diketahui persentase dari kepercayaan diri tersebut.
\end{abstract}

Kata kunci: tingkat percaya diri, panahan.

\begin{abstract}
The purpose of this study was to determine the level of confidence in the archery club archery club cumahi independant archery club in the city of Cimahi. The research method used in this research is descriptive research. This method is used to obtain data from the answers to the questionnaire. The population in this study were athletes POPDA Cimahi Mandiri Archery Club. The sample used was 18 athletes. The instrument used in this study was a questionnaire distributed via google form. The data analysis used in this study is contained in the main data, namely test questions. Data processing is done by creating a google form. The data that has been collected is then analyzed with the help of Ms Excel. The results in this study were $88.89 \%$ of the confidence level of the POPDA Cimahi Mandiri Archery Club athletes felt the influence of the confidence level on the results of the shot and the percentage of that confidence could be seen.
\end{abstract}

Keywords: confidence level, archery.

\section{PENDAHULUAN}

Olahraga Panahan merupakan salah satu cabang olahraga yang sudah ada sejak dulu dan terus berkembang mengikuti perkembangan zaman. Panahan merupakan suatu cabang olahraga yang mempunyai karakteristik tersendiri dibandingkan cabang olahraga lainnya. Pada dasarnya cabang olahraga panahan merupakan gabungan antara olahraga dan seni. Disebut olahraga karena menggunakan otot-otot fungsional, seperti trapezius, tricep dan deltoid dan juga. membutuhkan ketahanan fisik. Disebut seni karena membutuhkan sentuhan jiwa yang halus, kesabaran, keuletan dan ketahanan mental (Nawir, 2011).

Correspondence author: Veny Juniarni Hardi/Ali Budiman/Imam Riyadi, STKIP Pasundan, Indonesia.

Email: Venyjunihardi@gmail.com / Aliitock01@gmail.com 
Olahraga ini termasuk salah satu olahraga terukur. Ketepatan mengenai sasaran adalah hal yang paling mutlak untuk seorang pemanah (Hardi \& Nurama, 2019). Dalam permainan ini, setiap pemain harus mampu menembakkan anak panahnya mengenai sasaran yang telah ditentukan (Kim et al., 2019; Tan et al., 2016).

Dalam era modern saat ini panahan menjadi olahraga yang dipertandingkan hingga tingkat olimpiade. Saat ini olahraga panahan di naungi oleh FITA (Fédération Internationale de Tir à l'Arc) sedangkan di Indonesia sendiri panahan berada di bawah naungan PERPANI (Persatuan Panahan Indonesia). Panahan merupakan salah satu cabang andalan Indonesia dalam mendulang medali di berbagai kejuaraan seperti di ajang olimpiade, Asian games dan juga Sea Games. Dalam pertandingan panahan, pemenang di lihat dari seberapa banyak poin yang di dapat dari hasil tembakannya.

Panahan mengacu pada bentuk gerak yang dikerjakan dengan kombinasi terpadu dan menjelma dari setiap bagian anggota tubuh dari komponen-komponen kemampuan motorik seperti : kekuatan, keseimbangan, reaksi, dan ketepatan. Dengan koordinasi yang sesuai dan tata urutan gerak yang selaras akan terbentuk rangkaian gerak artistik yang menarik yang berpengaruh pada ketepatan memanah.

Dalam panahan sendiri terdapat sembilan teknik dasar dalam memanah yaitu: 1) cara berdiri (stance), 2) cara memasang ekor panah (nocking), 3) posisi setengah tarikan (set up), 4) menarik tali (drawing), 5) penjangkaran (anchoring), 6) menahan sikap memanah (holding), 7) membidik (aiming), 8) melepaskan anak panah (release), dan 9) sikap lanjutan (follow through). Gerakan-gerakan dasar tersebut sangat penting dalam olahraga panahan, dimana jika pemanah dapat melakukan gerakan dasar tersebut dengan baik maka hasil pun akan baik.

Namun, tidak hanya teknik saja yang harus dikuasai oleh seorang atlet panahan. Untuk bisa memanah tepat sasaran, para pemanah membutuhkan konsentrasi, focus dan percaya diri yang tinggi (Callaway et al., 2016; Choi \& Ok, 2016; Hardi \& Nurama, 2019; Park et al., 2016).

Penelitian sebelumnya telah memaparkan bagaimana efek dari tingkat konsentrasi terhadap hasil memanah (Hardi \& Nurama, 2019) dan juga bentuk latihan fisik untuk meningkatkan kemampuan teknik memanah (Hardi, 2019), namun belum terpaparkan mengenai sejauhmana dampak tingkat konsentrasi terhadap hasil memanah.

Maka dari itu artikel ini betujuan untuk meneliti seberapa besar dampak dari tingkat konsentrasi seorang atlet terhadap hasil memanah di Cimahi Mandiri Archeri Club.

\section{METODE}

Metode dalam penelitian ini menggunakan metode deskriptif, metode ini digunakan untuk mendapatkan data dari hasil jawaban pada angket (Sugiyono, 2017). 
Populasi dalam penelitian ini adalah 18 atlet POPDA Cimahi Mandiri Archery Club. Dalam penelitian ini penulis akan mengambil teknik total sampling atau jenuh keseluruhan dari populasi akan diambil menjadi sampel penelitian yakni sebanyak 18 atlet POPDA Cimahi Mandiri Archery Club. Dalam penelitian ini melakukan kuisioner atau angket berdasarkan dari teori Sport Confidence yang dikembangkan oleh Robin Vealley (1986). Sport Confidence adalah kepercayaan yang dimiliki seorang individu tentang kemampuannya untuk dapat sukses di bidang olahraga. Teknik penilaian dalam angket yang digunakan tersebut menggunakan skala Guttman (Frey, 2018). Setelah diujicobakan, diketahui tingkat reliabilitas skala ketepatan dan percaya pada penelitian ini adalah 0.77 .

Dalam menentukan analisis data, diperlukan data yang akurat serta dapat dipercaya yang nantinya dipergunakan dalam penelitian yang dilakukan penulis. Analisis data dalam penelitian ini dibantu oleh program SPSS dan micosoft excel.

\section{HASIL DAN PEMBAHASAN}

\section{Hasil}

Berikut ini peneliti uraikan hasil penelitian yang telah dilakukan untuk mengetahui tingkat percaya diri atlet panahan cimahi mandiri archey club. Data yang diperoleh dari hasil penelitian tersebut selanjutnya diolah dan dianalisis dengan menggunaan penyebaran angket dan diolah dengan Microsoft excel. Adapun hasil pengolahan data yang akan penulis uraikan dan terdapat 2 varabel, tiga indikator untuk mengukur hasil pada penelitian.

Tabel 1. Tingkat percaya diri atlet panahan cimahi mandiri archery club

\begin{tabular}{ccc}
\hline Skor Ideal & Skor Responden & Presentase \\
\hline $8 \times 1 \times 18=144$ & 128 & $\times 100=88,89 \%$ \\
\hline
\end{tabular}

Dari tabel di atas, dapat dilihat bahwa tingkat percaya diri atlet panahan cimahi archery club adalah $88,89 \%$.

Tabel 2. Sub indikator (konsentrasi pada efisiensi kognitif)

\begin{tabular}{ccc}
\hline Skor Ideal & Skor Responden & Presentase \\
\hline $2 \times 1 \times 18=36$ & 23 & $-\times 100=63,89 \%$ \\
\hline
\end{tabular}


Dari tabel 2 di atas, menunjukkan bahwa pada konsentrasi tingkat percaya diri atlet. Responden merasa bahwa konsentrasinya masih belum cukup baik.

Tabel 3. Sub indikator (otot lengan pada kekuatan otot)

\begin{tabular}{ccc}
\hline Skor Ideal & Skor Responden & Presentase \\
\hline $1 \times 1 \times 18=18$ & 11 & $-\times 100=61,1 \%$
\end{tabular}

Dari tabel 3 di atas, menunjukkan bahwa pada otot lengan tingkat percaya diri atlet. Responden merasa belum memiliki kekuatan otot lengan yang belum terlalu kuat.

Tabel 4. Sub indikator (otot kaki pada kekuatan otot)

\begin{tabular}{ccc}
\hline Skor Ideal & Skor Responden & Presentase \\
\hline $1 \times 1 \times 18=18$ & 12 & x $100=66,67 \%$ \\
\hline
\end{tabular}

Dari tabel 4 di atas, menunjukkan bahwa pada otot kaki tingkat percaya diri atlet. Responden merasa belum memiliki kekuatan otot kaki yang cukup kuat.

Tabel 5. Sub indikator (stamina pada kekuatan otot)

\begin{tabular}{ccc}
\hline Skor Ideal & Skor Responden & Presentase \\
\hline $1 \times 1 \times 18=18$ & 13 & x $100=72,2 \%$ \\
\hline
\end{tabular}

Dari tabel 5 di atas, menunjukkan bahwa pada stamina tingkat percaya diri atlet. Responden merasa bahwa stamina nya sudah baik dalam bertanding.

Tabel 6. Sub indikator (ketajaman mata pada kekuatan otot)

\begin{tabular}{ccc}
\hline Skor Ideal & Skor Responden & Persentase \\
\hline $1 \times 1 \times 18=18$ & 15 & x $100=83,3 \%-$ \\
\hline
\end{tabular}

Dari tabel 6 di atas, menunjukkan bahwa ketajaman mata tingkat percaya diri atlet. Responden merasa bahwa ketajaman mata nya sangat baik..

Tabel 7. Sub indikator (fokus pada efisiensi kognitif)

\begin{tabular}{ccc}
\hline Skor Ideal & Skor Responden & Persentase \\
\hline $2 \times 1 \times 18=36$ & 25 & $\times 100=69,4 \%$ \\
\hline
\end{tabular}


Dari tabel 7 di atas, menunjukkan bahwa fokus tingkat percaya diri atlet. Responden merasa bahwa fokus nya sudah cukup baik.

Tabel 8. Sub indikator (pengambilan keputusan pada efisiensi kognitif)

\begin{tabular}{ccc}
\hline Skor Ideal & Skor Responden & Persentase \\
\hline $1 \times 1 \times 18=18$ & 12 & x $100=66,67 \%-$
\end{tabular}

Dari tabel 8 di atas, menunjukkan bahwa pengambilan keputusan tingkat percaya diri atlet. Responden merasa bahwa pengambilan keputusan nya sudah cukup baik.

Tabel 9. Sub indikator (pantang menyerah pada keuletan)

\begin{tabular}{ccc}
\hline Skor Ideal & Skor Responden & Persentase \\
\hline $1 \times 1 \times 18=18$ & 17 & $\times 100=94,4 \%-$ \\
\hline
\end{tabular}

Dari tabel 9 di atas, menunjukkan bahwa pantang menyerah tingkat percaya diri atlet. Responden merasa bahwa sikap pantang menyerahnya sudah sangat baik.

\section{Pembahasan}

Dengan melihat hasil di atas dapat terlihat terdapat hasil yang bervariasi dari tingkat percaya diri atlet POPDA Cimahi Mandiri Archery Club. Penelitian ini berkaitan dengan penelitian yang telah dilakukan sebelumnya yang berjudul "Hubungan tingkat konsentrasi terhadap ketepatan memanah" dan pada kesimpulannya terdapat pengaruh tingkat konsentrasi terhadap ketepatan memanah, dan apa yang memengaruhi tingkat kosentrasi itu ialah fokus dan kestabilan antara percaya diri serta kecemasan atlet tersebut (Hardi \& Nurama, 2019).

Penyebaran angket di lakukan untuk mengetahui tingkat percaya diri pada atlet cimahi mandiri archery club. Karena percaya diri itu tidak hanya untuk pertandingan saja akan tetapi untuk hal lain seperti melakukan hal secara Bersama untuk memecahkan masalah dan lain lain.

Dengan uraian di atas maka dapat dikatakan kaitan antara percaya diri dan kecemasan terhadap tingkat konsentrasi ketepatan memanah. Hal ini diakibatkan oleh keadaan emosional yang terjadi mendadak/pada waktu tertentu yang ditandai dengan kecemasan, takut, tegang, dan biasanya kecemasan ini terjadi saat menjelang pertandingan, kecemasan lainnya yang terjadi pada atlet biasanya takut gagal dalam pertandingan (Tangkudung, 2018). 


\section{KESIMPULAN}

Beradasarkan dari hasil penelitian yang dilakukan peneliti maka dapat dikatakan kaitan antara percaya diri dan kecemasan terhadap tingkat konsentrasi ketepatan memanah. Hal ini diakibatkan oleh keadaan emosional yang terjadi mendadak/pada waktu tertentu yang ditandai dengan kecemasan, takut, tegang, dan biasanya kecemasan ini terjadi saat menjelang pertandingan, kecemasan lainnya yang terjadi pada atlet biasanya takut gagal dalam pertandingan. Dan akhirnya memengaruhi hasil yang diperoleh menjadi negatif atau jelek

tingkat percaya diri berperan terhadap ketepatan tembakan atlet panahan. Serta percaya diri berjalan secara linear Bersama kecemasan agar menghasilkan tembakan yang tepat, selain itu hasil dari tingkat kepercayaan ini bisa sebagai pedoman agar tingkat percaya diri atlet dapat ditingkatkan. Dengan begitu dapat mengontrol secara penuh kondisi emosional atlet itu sendiri.

\section{DAFTAR PUSTAKA}

Callaway, A. J., Wiedlack, J., Heller, M., \& Callaway, A. J. (2016). Identification of temporal factors related to shot performance for indoor recurve archery archery. Journal of Sport Sciences, 0414(September). https://doi.org/10.1080/02640414.2016.1211730

Choi, S., \& Ok, G. (2016). The Role of Gukgung in the Success of South Korean Archery The Role of Gukgung in the Success of South Korean Archery. The International Journal of the History of Sport, 3367(November), 1-18. https://doi.org/10.1080/09523367.2016.1237507

Frey, B. B. (2018). Guttman Scaling. The SAGE Encyclopedia of Educational Research, Measurement, and Evaluation, 1-5. https://doi.org/10.4135/9781506326139.n298

Hardi, V. J. (2019). Frekuensi Latihan Pliometrik (Push Up dan Pull Up) terhadap Prestasi Memanah. Jurnal Olahraga, 5(1), 45-52. https://doi.org/10.37742/jo.v5i1.93

Hardi, V. J., \& Nurama, D. (2019). Hubungan Tingkat Konsentrasi terhadap Ketepatan Memanah. 5(1).

Kim, J. T., Kim, S. Y., \& Oh, D. W. (2019). An 8-week scapular stabilization exercise program in an elite archer with scapular dyskinesis presenting joint noise: A case report with oneyear follow-up. Physiotherapy Theory and Practice, 35(2), 183-189. https://doi.org/10.1080/09593985.2018.1442538

Nawir, N. (2011). Kontribusi Kekuatan Otot Tangan Dan Daya Tahan Otot Lengan Dengan Kemampuan Memanah Jarak 30 Meter Pada Atlet Panahan Sulawesi Selatan. Jurnal Pendidikan Kepelatihan Olahraga, 2(3), 122-132.

Park, J., Tan, T., \& Park, H. (2016). Interrogating the Key Policy Factors Behind South Korea ' s Archery Success Interrogating the Key Policy Factors Behind South Korea' s Archery Success. The International Journal of the History of Sport, 3367(June). https://doi.org/10.1080/09523367.2016.1173673

Sugiyono. (2017). Metode Penelitian Kuantitatif, Kualitatif dan R\&D. Alfabeta.

Tan, S. L., Koh, K. T., \& Kokkonen, M. (2016). The perception of elite athletes' guided selfreflection and performance in archery. Reflective Practice, 3943(May). https://doi.org/10.1080/14623943.2016.1146582 
Journal of Physical and Outdoor Education, 2 (2) 2020 | 221-227

ISSN : 2721-9992 (Online)

ISSN : 2656-1883 (Print)

Tangkudung, J. (2018). Sport Psychometrics Dasar-dasar dan Instrumen Sport Psikometri. Rajagrafindo persada. 